\title{
31176013455341
}

\section{Qualification Needs for Advanced Integrated Aircraft}

Dale A. Mackall

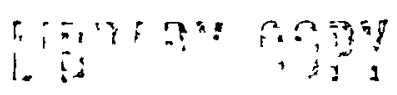

SEP 179985

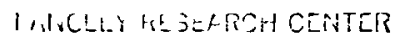

D'ERATY, IIASA

"INATON, VIRGII!li. 
NASA Technıcal Memorandum 86731

\section{Qualification Needs for Advanced Integrated Aircraft}

Dale A Mackall

Ames Research Center, Dryden Flıght Research Facılıty, Edwards, Calıfornıa

\section{N/Sก}

National Aeronautics and

Space Administration

Ames Research Center

Dryden Flight Research Facility

Edwards, Calıfornı 93523 


\title{
QUALIFICATION NEEDS FOR ADVANCED INTEGRATED AIRCRAFT
}

\author{
Dale A. Mackall*
}

NASA Ames Research Center

Dryden Flight Research Facility

Edwards, California

\section{Abstract}

In an effort to achieve maximum aircraft performance, designers are integrating aircraft systems. The characteristics of aerodynamics, vehicle structure, and propulsion systems are being integrated and controlled through embedded, often flight-critical, electronic systems. This paper addresses the qualification needs for such highly integrated aircraft systems. Based on flight experience with research aircraft, a set of test capabilities is described which allows for complete and efficient qualification of advanced integrated aircraft.

\section{Nomenclature}

DEEC digital electronic engine control

DEFCS digital electronic flight control system

EMD engine model derivation

EMI electromagnetic interference

FMET fallure modes and effects testing

HIDEC highly integrated digital engine control

ISA integrated servoactuator

ITF Integrated Test Facility

LVDT linear variable displacement transducer

RPRV remotely piloted research vehicle

STOL short takeoff and landing

\section{Introduction}

From the first integrated system program, the YF-12 cooperative control program, to the most recent, the $x-29$ forward-swept wing program, the trend in alrcraft research at the Ames Research Center, Dryden Flight Research Facility has been to control the previously adverse or undesirable interactions between subsystems to improve performance. At certain flight conditions the YF-12 propulsion system's bypass door operation had considerable undesired control authority. 1 By using the undesired bypass door effect through proper electronic control, the flightpath performance of the alrcraft was improved by a factor of 10 . The $x-29$ digital flight control system allows the $35-$ percent staticly unstable aerodynamic configuration to fly with level l flying qualities.
The use of digital electronic control systems to take advantage of the undesirable or unique characteristics of an aircraft system has led to a new class of advanced integrated alrcraft. A leading issue in the development of this new class of aircraft is the complete and efficient testing or qualification of the aircraft's systems and performance. The improved performance obtained by the integration places an equivalent increase in flight criticality for the avionics that accomplishes it. Full-authority flight control for staticly unstable airframes is a prime example. More avionics systems, such as the weapon systems in an integrated flight-fire control system, are becoming flight safety related. The need to assure safe and efficient flight testing for this new class of alrcraft places new requirements on the test capabilities for aircraft qualification.

There are many steps in qualifying an alrcraft for flight, however, this paper addresses only the validation of the design to a system performance specification, once all the subsystem testing has been completed. This testing is to validate the performance of a design, and is not intended to show proper implementation. "Integrated systems aircraft" is defined and the requirements for testing this type of aircraft are discussed. Such requirements include testing capabilities, and the type of facility in which to perform the tests namely, the proposed NASA Ames-Dryden Integrated Test Facility.

\section{Integrated Systems Aurcraft}

Popular new terms over the past few years include the "integrated systems aircraft" and "synergistic design." To the degree possible, every alrcraft has used the individual components of its design to provide a cooperative, effective total system (synergism), given the technology avallable at the time. Today's highly integrated aircraft are uniquely characterized by (1) the extent to which the aircraft disciplines or subsystems are combined, and (2) the use of embedded digital control systems to accomplish the integration. The primary distinction from the past is the flight safety dependence of the integrations.

System integration can be categorized as either functional or subsystem integration. Functional integration occurs when basic aircraft disciplines, such as aerodynamics, structures, or propulsion, are blended through a control system to provide new or improved functions. Examples of functional integrations include staticly unstable airframes requiring full authority control systems, the structural integration providing maneuver-load control and flutter-suppression systems, and 
maneuverability and performance gains expected from integrated propulsion control.

Two alrcraft currently in flight test at Ames-Dryden in the functionally integrated category are the $x-29$ forward-swept wing and the F-15 alrcraft being used for the highly integrated digital engine control (HIDEC) program. ${ }^{2}$ Figures 1 and 2 show an overview of the $X-29$ alrcraft and its digital flight control system. Figures 3 and 4 give an overview of the HIDEC systems. Primary interactions in the $x-29$ aircraft are between the aerodynamics (35-percent staticly unstable), the structure, and the flight control system. The HIDEC is investigating interactions between the flight control and propulsion control systems. Reference 3 provides an excellent review of integrated systems aircraft worldwide.

Subsystem integration results from the implementation of the systems that achieve the functional integration. Subsystems include electrical power, actuation and hydraulics, pilot displays, avionics, and, in the case of the military, weapon systems. Full-authority flight control requires the integration of an electrical system to provide full-time, safety-critical power to the control system. Similarly, the flight control system must be interfaced to the actuation system in a manner that is tolerant to faults. These interfaces, or subsystem integrations, are a direct result of the demands placed by the functional integration to control a staticly unstable airframe. Another type of subsystem integration is information fusing or resource sharing. This resulted from the use of digital avionic systems and their data bus architectures. The air data computer can provide data to the flight control system, navigation system, weapon system, and pilot's displays. Raw data and calculated results can be shared by various subsystems.

Integrated systems aircraft can be defined as those that achieve a significant performance gain through functional integration. The functional integrations often use undesirable interactions in a controlled, beneficial manner, making the loss of the control system unacceptable and of ten unsafe.

Flight experience with the earliest integrated systems aircraft, those with digital flight control systems, has uncovered several unique anomalies that help identify areas where integrated testing capabilities are needed. These anomalies include

1. Limit-cycle oscillations caused by differences between the iron-bird simulation and the alrcraft actuator hysteresis. Inclusion of the actual a ircraft systems during ground test would have avoided this flight anomaly.

2. Loss of two out of three digital flight control channels. This was caused by many factors, sensor noise and asynchronous channel operation being primary. The problem was undetected during ground test because of inadequate models of sensor noise and because exact conditions of fallure were not in the test matrix.
3. Rudder oscillation with frequency proportionate to engine rpm. The flight control lateral accelerometer detected engine vibrations and fed the control laws. Inclusion of the flight vehicle with the engine operating during ground test would have avorded the flight anomaly.

4. Rapid flight control mode changes caused by an avionics system fallure. Problem was not repeatable, and the cause was never found. This serrous integration problem (the rapid flight control mode changes caused by the avionics system fallure) suggests that improved test efficiency could have avorded the flight anomaly.

5. Unexpected inability to lower landing gear in a remotely piloted vehicle, caused by fallure of one of two uplink command receivers. Multiple hardware and software changes, coupled with inefficient fallure modes and effects retesting, allowed anomaly.

This partial list of anomalies, along with other flight experience, indicates the need for integrated systems testing. The capabilities described in this paper are currently in various stages of development, all are believed to be needed for successful qualification of integrated systems aircraft.

\section{Integrated Systems Testing}

Integrated systems alrcraft require integrated systems testing, in addition to the standard individual component testing that is performed on conventionally designed aircraft. Table 1 lists the types of integrated system tests and provides a few examples of component tests for comparison. This section defines integrated system testing, the environments necessitated by it, and how this testing relates to a particular integrated systems application.

One aspect of integrated system testing that makes it unique from other testing is the environment or configuration that is needed. Experience at the Dryden Flight Research Facility has shown that all the interacting systems must be operating together, in an environment that best represents flight, to successfully test an integrated systems aircraft. Required are the embedded digital control system, the airframe, the aircraft subsystems, and the propulsion system. Where aspects of the flight environment or configuration are not possible, detailed simulation models must be included. Typically, the aircraft aerodynamics is a primary model, along with the propulsion system model. Depending on the particular application and such items as the avallability of the alrframe, other models may also include the actuators, airframe structural modes, maneuvering target alrcraft, threats, and perhaps the integrated control algorithms. Figure 5 shows an example of an aircraft in the aerodynamic loop configuration, and Fig. 6 , a hot-bench configuration that utilizes the flight electronics hardware only. The hot-bench configuration uses more models than the aircraft-in-the-loop configuration, and the alrcraft subsystems, such as the electrical system, are not included. Six cate- 
gories of integrated system testing are described in the following sections.

Farlure Modes and Effects Testing

Fallure modes and effects testing (FMET) assures that the integrated control system design identifies fallures and reconfigures the system correctly in response to those fallures. Because of the criticality of the system, redundant, fault-tolerant hardware designs are required. Triplex and quad redundancy are used for most digital flight control systems. FMET validates the performance of the fault tolerant design.

Unlike fallure modes and effects analysis which examines the system design to determine fallure paths leading to loss of control, FMET tests the real hardware operating the flight software. FMET determines the effects of single fallures as well as combinations of fallures that can lead to loss of control. The fault detection, identification, and reconfiguration of fallures have been accomplished within the flight software, making the software an essential part of any fallure modes evaluation. In integrated subsystems dircraft, FMET also assures that fallures of a subsystem are contained within its allowed boundaries.

FMET is performed by inducing simulated fallures in sensors, computer components, communication links, the actuation system, and pilot displays, and then evaluating the effects. Effects are evaluated in terms of the 1 mpact on reliability, the proper detection and reconfiguration by the system, and the stability and control performance of the reconfigured system. Depending on the component being falled, several fallure modes are examined. Null, hard-over, ramp, and bias fallures are typical fallure modes exercised for sensor inputs. FMET is usually nondestructive testing, with fallure modes being simulated or induced over nominal values.

Stability and Control Testing

Any physical system, whether it be an aircraft, a structure, an engine, or any combination of the three, that has its basic characteristics modified through the use of an active control system, must be tested for adequate stability and control throughout its development. Testing requires a closed-loop configuration to determine proper responses to step inputs, frequency sweeps, and pilot commands. Table 2 lists the typical stability and control tests and the criteria examined for a successful test. The integrated system configuration of this test is performed with the alrcraft in the loop so that all the system nonlinearities of flight are present, and to uncover any unexpected interactions that may exist. Test comparisons are made to the stability and control tests which are done during development of systems that use linear models.

\section{Electromagnetic Interference Testing}

Electromagnetic Interference (EMI) testing is performed to determine any undesirable effects one subsystem may have on another because of electromagnetic interactions. Because of the amount of electronic equipment and possible modes in which the equipment can operate, the EMI test matrix can grow very large. Testing all the possibilities in an integrated systems aircraft, where a large number of the electronic components are required for safe flight, becomes a difficult task. To date, EMI testing has not been performed with the aerodynamics loop closed around the control system because the flight control system has been a dedicated system without a large number of critical interfaces to other systems. In addition, a considerable amount of testing is performed with the engine operating, making closed-loop operation difficult.

Integrated systems testing for electromagnetic interference will require more effort to complete, to assure that the critical electronic components are compatible for all their operating modes. The capability to perform the tests with the engine running and the aerodynamic loops closed around the control system is needed.

\section{Integration Effects and Sensitivity Testing}

Integration effects and sensitivity testing is a unique category for integrated systems aircraft, which concentrates on evaluating the performance effects of the integrated design and what sensitivity the performance may have to changes in various parameters. Each integrated system design is unique therefore, the actual testing and parameters involved will vary. However, when two previously independent systems become reliant on each other, their effects on and sensitivities to each other must be determined. In an integrated flight-fire control system, the stability and control effects that the fire control system has on the flight control system must be evaluated with all systems interacting. The fault-tolerant performance of the overall system must also be evaluated and the sensitivity to different fallure modes defined.

An example of a digital flight control sensitivity test is determining the effects of changes in the effectiveness of the control surfaces on stability and control characteristics. This test is done to evaluate the effects of model uncertainties on performance.

\section{Mission Evaluations}

Mission evaluation tests are identified by the fact that the pilot is evaluating the integrated aircraft systems ' performance. Evaluations are made for flying qualities, displays, and pilot controls. Testing includes both fallure-free operation and operation with fallures induced. Integrated flight-fire control evaluations may include gross acquisition, tracking, and fragment avoldance after weapon release. An integrated propulsion control system for short takeoff and landing (STOL) would require piloted evaluations of landings and engrne-out performance. As the system matures, the mission evaluations are used to assure that flight test points are evaluated on the ground before actual flight testing. This 
provides the double service of pilot training, and of detecting any unexpected anomalies that may be latent in the system, surfacing when certain conditions arise.

Mission evaluations are a subset of the previous three tests, performed with a pilot, in the environment that best represents flight.

\section{Revalidation}

Throughout the final development and flight test of any control system, changes are made to make improvements and correct discrepancies. Figure 7 shows the discrepancies and corresponding software changes made on one of the Ames-Dryden research alrcraft. Any system, whether research, military, or commercial, will eventually be subject to change. Integrated systems alrcraft, because of their interactive nature, require careful revalidation of the system for changes made to any of the subsystems. The five tests described previously must be scrutinized to define a sufficient subset of tests that requalify the alrcraft.

FMET is frequently rationalized as not needed. It is the most difficult and time-consuming test to perform, and the probability of a fallure in a given flight is comparatively low. The criticality of the integrated systems aircraft requires that FMET be a part of the revalidation effort, otherwise, single fallures will cause unexpected, perhaps disastrous, results. The inability to lower the gear in the remotely prloted vehicle cited earlier could have been avoided if FMET had been performed after changes were made.

\section{Capabilities to Improve Completeness and Efficiency}

Capabilities for complete and efficient testing of integrated systems aircraft are needed to support both initial qualification and flight test operations. Complete testing is required because of the criticality the systems have, and the need to assure safe flight test. Test efficiency is needed to accomplish the increased amount of test ing required before flight test and to minimize the downtime for resolving discrepancies discovered during flight test. Completeness and efficiency are closely related. Given a set time frame, test efficiency will allow more testing to occur, improving completeness.

The test matrix (and therefore the number of test conditions) grows exponentially as the number of interdependencies increases. Aircraft stability and control has always been dependent on the aerodynamics, but has now become dependent on the control algorithms, the weapon systems, and the propulsion system characteristics (such as vectored thrust). These new dependencies increase the amount of testing needed. The rationale for complete and efficient testing, along with the desired capabilities to accomplish them, are shown in Table 3. To achieve completeness requires providing capabilities for increased understanding of the system being tested for determining proper test matrices, for increasing the visibility into the system, and for reducing the number of modeling errors through more efficient use of flight equipment. To achieve efficiency requires automating the test process, centralizing the test information, providing for quick test setup, and allowing for easy isolation of interactive systems for troubleshooting.

\section{Test Completeness}

Documentation of the flight hardware, the software operating in each flight computer, signal interfaces, and the functional design are all needed to perform integrated systems testing. This documentation is currently only available in hard copy form, often welghing more than one person can carry. The need for an online description of system operation has been shown by such simple examples as word processing software for personal computers which have online help functions. Placing a system description for a control system in a flight computer would not be appropriate, but a system description must be avallable to the test engineer. Armed with a complete system description, the test engineer can wisely choose test matrices, determine test parameters to monitor, and be in a better position to resolve discrepancies that occur during testing.

The integrated systems aircraft gives the potential of having problems surface in areas that are not being tested directly. Testing a high-current device that loads the electrical bus could affect the operation of any one of the embedded flight computers through EMI. The extensive use of embedded flight computers also means that a majority of the system integration is being done by the software. Instrumentation of the system under test means that one must monitor the different integrated systems, hardware and software, and the aircraft subsystems during test operations. Instrumentation of the software must be considered early in the design to provide access to internal calculations at the rates needed.

Modeling deficiencies can consist of the lack of models for system interactions not believed to be important, as well as uncertainties in models for such things as aerodynamics or the propulsion system. The inability to know and model all the interfaces and interactions that exist between the aircraft subsystems has lead to the inclusion of the alrcraft and its flight equipment in the test environment. For example, a control algorithm written in FORTRAN and operating on a mainframe computer would have different characteristics from a flight version. The effect of those differences on system performance is difficult to identify. The easiest solution to the problem is the inclusion of the flight hardware when performing tests. This system "burn-1n" is essential for detecting interface problems and achieving maturity in the design.

When qualifying integrated systems aircraft, the model of the operating environment must be 
carefully considered to determine its effects on the system. Environmental factors primarily include vibration, temperature, and for piloted simulations, the visual display. Placing an entire aircraft in an environmental chamber capable of thermal cycling and three axis vibration is not feasible, therefore, the effects of these factors must be modeled during testing. Vibration can be inodeled by imposing noise on top of sensor values and by testing with the engine operating. Trmperature effects must be measured for sensors and actuators and the appropriate sensitivity testing performed. Hot-bench testing allows the flight hardware to be operated within a thermal chamber and the aerodynamic loop closed around the flight control system.

The piloted simulation tasks of mission evaluations require a complete and coordinated set of visual and instrument displays. Integrated systems aircraft are using head-up displays, digital maps, and multifunctional displays as primary pilot instruments. These visual displays, coupled with the out-the-window display, must present a coordinated, realistic flight environment to the pilot. To allow testing with the aircraft in the loop, and to drive the visual displays, requires special considerations during the design of the a 1 rcraft.

\section{Test Efficiency}

Increasing test efficiency provides the time to perform the complete testing needed to qualify integrated systems for flight test. Test eff $1-$ ciency also reduces flight test cost by minimizing the downtime associated with identifying and resolving discrepancies from flight test. With test costs for digital flight control system qualification running as much as $\$ 1$ million a month on a given program, improving test efficrency is essential.

Automating the test process is the first step in improving test efficiency. To do this one must first examine the steps performed when conducting a test. They include (1) writing the test procedures, (2) initiating and monitoring the test, (3) analyzing the results for test success, and (4) displaying and documenting the results. Table 4 compares the current manual approach of testing to an automated approach. By putting the simulation and flight systems under control of the automated test system, all the test steps can be interactively controlled by the test engineer. The automated test system requires data base management and analysis software, along with graphical displays and hard copy documentation - all possible with today's engineering work stations. With the automated test system, the number of tests performed and the number of parameters that can be monitored and analyzed is not $11 \mathrm{mited}$ by the time avallable for testing but by the computational power of the test system.

One obstacle to efficient test operations has been the lack of centralized control and display of test data. Simulation data and operational control have not been avallable at the alrcraft, and only minimal aircraft data were avallable at the simulation. Control of the alrcraft systems was done entirely at the vehicle. A major goal of the automated test development is to rectify the problem by bringing together the aircraft and the simulation operations at one central test station. Synergistic flight vehicles require a synergistic approach to their qualification.

\section{Flight Test Support}

In addition to all the above capabilities, two unique capabilities are needed to support the integrated systems aircraft during flight test. Flight test anomalies of this type of aircraft must be thoroughly understood, resolved, and corrected in as short a time as possible to keep flight test cost down. Thoroughly understanding a problem and providing quick turnaround have not been easily accomplished in the past, as the goals tend to be mutually exclusive. Two capabilities will help the situation. First is to allow for quick setup of the aircraft with the simulation so that the conditions of the anomaly can be reproduced quickly. Second is to allow isolation of the interactive subsystems so that the effects of a falling subsystem can be separated from those induced by its interactive partners. In an integrated propulsion-flight control system, this would provide the ability to easily test flight control and propulsion control independently, then combine them for integrated testing. This capability would require that the test system have control over the aircraft systems, and that the necessary aircraft interfaces be provided.

Each of the capabilities discussed have some application to the different integrated systems tests. Depending on the particular integrated systems aircraft design and the specific test, certain capabilities will prove to be more valuable than others. For example, mission evaluations which require piloted simulation cannot be automated to the extent of a stability and control test, in which a specific test is repeated at numerous different flight conditions.

In summary, it is believed that the development of these capabilities will provide for efficient and complete qualification of the integrated systems aircraft flyıng now and in the future.

\section{Application to Failure Modes and Effects Testing}

Fallure modes and effects testing for a typical digital flight control system is examined to show how the integrated systems test capabilities can be applied. Several factors must be considered when determining FMET cases for digital control system, including aircraft state, device to be falled, fallure mode, and pilot inputs (Table 5). This results in a four-dimensional matrix of possible test combinations, impossible to thoroughly test manually. In designs where the control law characteristics are not decoupled from the fault-detection $\log 1 \mathrm{c}$, changes in aircraft state, such as Mach number and altitude, will change control law gains and affect the perfor- 
mance of the fault-detection logic. Test matrices of a million test cases are easy to obtain.

Certain capabilities are needed to perform even the basic FMET cases. They include having the real flight equipment under test and having the flight systems thoroughly instrumented. Two of the test capabilities are especially suited to address the problem of the large test matrix online system description and test automation.

Reducing an FMET test matrix is very difficult because there 15 always the chance that an unexpected interaction will cause a single fallure to develop into something more serious. However, by using an online system description that has been verified as accurate by previous subsystem testing, a test engineer can make intelligent choices when determining the validity of a test case. The online description must allow one to query the design data to determine whether relationships exist between test conditions and subsystems. This has been accomplished to a limited extent on one flight program. Advances in computer science provide several approaches to the online data-base capability; they include relational data-base management systems and artificial intelligence.

The second capability, test automation, shows great promise for handing the test matrices of FMET. The earliest stages of test automation for FMET were during the F-8 digital fly-by-wire program in the midseventies. Sensor redundancy management software in the flight control computers was tested using an automated test pattern that feeds each of the triplex sensors. All aspects of the software were exercised by a 35-second sequence (Fig. 8). Analysis of the results required transferring of data tapes and visual inspection, however, the time needed to qualify the software was greatly reduced. By concentrating the test data and by automating the entire test process from test initiation through analysis and documentation, it is expected that large FMET matrices can be completed in an acceptable time frame.

\section{The Integrated Test Facility}

The Integrated Test Facility (ITF, Fig. 9) is a newly proposed facility to be located at Ames-
Oryden. The facility would house several existing functions, as well as provide for some new functions necessary to qualify integrated systems aircraft. The ITF brings together the aircraft, simulation systems, and engineering staff, providing a unifiea test environment. A layout of the $\mathrm{facl-}$ lity is shown in Fig. 10. Included is hangar space and aircraft services to support up to six a reraft. Three hangar bays can also be configured to house one larger aircraft. The center section of the building houses the simulation systems, placing them in close proximity to all six hangar test bays. The engineering staff is located in the front of the building, with ample room for visiting contractors who support the flight test programs. The facility would support classified programs.

By providing the ability to operate all the aircraft systems in the test environment, the ITF would provide the capabilities necessary to qualify integrated systems aircraft.

\section{Concluding Remarks}

Flight test experience with early integrated systems aurcraft has shown the difficulty and cost of qualifying and flight testing this new class of a rcraft. New capabilities must be developed to qualify the integrated systems aircraft to avoid delayed developments and increased risk during flight test. The Integrated Test Facility and test capabilities described herein are being developed to assure continued progress in the filight test of aeronautic programs.

\section{REFERENCES}

1. Schweikhard, William G., and Berry, Donald T., "Cooperative Alrframe/Propuision Control for Supersonic Cruise Aircraft," SAE Paper 740478, May 1974.

2. Burcham, Frank W., Jr., and Haerıng, Edward A., Jr., "Highly Integrated Digital Engine Control System on an F-15 Airplane," AIAA Paper 84-1259, June 1984.

3. Rediess, H.A., and Buckley, E.C., "Technology Review of Flight Crucial Flight Control Systems," NASA CR-172332, 1984. 
Table 1 Integrated system and component tests

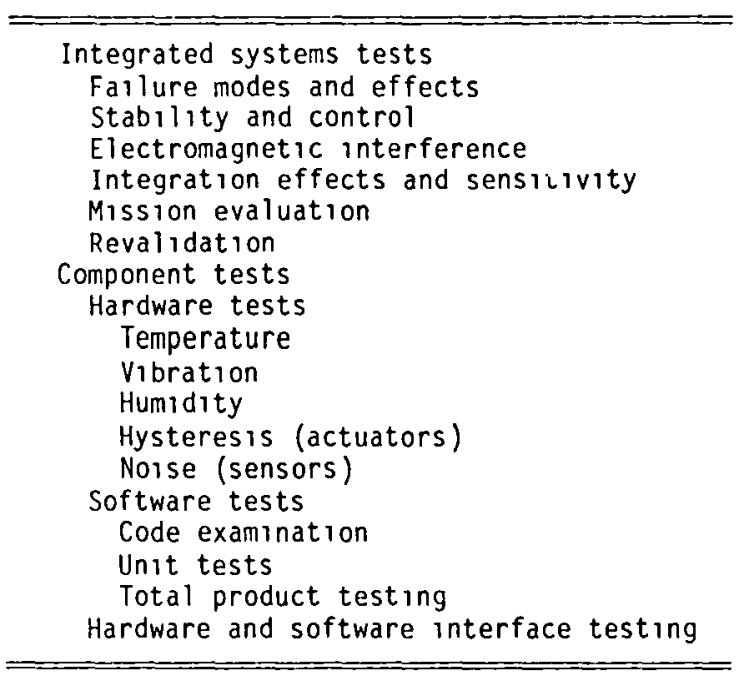

Table 2 Stability and control tests and criteria

\begin{tabular}{|c|c|c|}
\hline Test & Type & Criteria \\
\hline Step response & Time domain & $\begin{array}{l}\text { Frequency and damping } \\
\text { of response }\end{array}$ \\
\hline $\begin{array}{l}\text { Frequency response, } \\
\text { closed loop }\end{array}$ & Frequency domain & $\begin{array}{l}\text { Gain margins, phase } \\
\text { margins }\end{array}$ \\
\hline $\begin{array}{l}\text { Frequency response, } \\
\text { open loop }\end{array}$ & Frequency domain & $\begin{array}{l}\text { Comparison of flight } \\
\text { code to development } \\
\text { models }\end{array}$ \\
\hline Static gains & Time domain & $\begin{array}{l}\text { Comparison of sensor to } \\
\text { surface gains to } \\
\text { development models }\end{array}$ \\
\hline
\end{tabular}

Table 3 Capabilities needed for complete, efficient testing

\begin{tabular}{|c|c|}
\hline Completeness & Efficiency \\
\hline $\begin{array}{l}\text { Rationale - } \\
\text { Criticality of systems, safety } \\
\text { Minimize flight test anomalies } \\
\text { Capabilities - } \\
\text { Online system description for } \\
\text { a thorough understanding of } \\
\text { system under test and deter- } \\
\text { mining proper test matrices } \\
\text { Instrumentation of systems } \\
\text { under test to see detalled } \\
\text { response to stimulus } \\
\text { Inclusion of real equipment } \\
\text { to minimize modeling errors } \\
\text { Providing detailed models of } \\
\text { the systems operating } \\
\text { environment. }\end{array}$ & $\begin{array}{l}\text { Rationale - } \\
\text { Increasing size of test matrix } \\
\text { needed to qualify system } \\
\text { Minimize downtime during flight } \\
\text { Capabilities - } \\
\text { Automation of the test process } \\
\text { Performing test cases } \\
\text { Analysis of Results } \\
\text { Documentation } \\
\text { Centralized control and display } \\
\text { of test data } \\
\text { Quick setup of aircraft systems } \\
\text { for analysis } \\
\text { Isolation of individual inter- } \\
\text { related systems for trouble- } \\
\text { shooting. }\end{array}$ \\
\hline
\end{tabular}


Table 4 Comparisons of current manual test approach to an automated approach

\begin{tabular}{ccc}
\hline \hline Test phase & Current approach & Automated approach \\
\hline $\begin{array}{c}\text { Develop test } \\
\text { procedures }\end{array}$ & $\begin{array}{c}\text { Write verification and } \\
\text { validation tests } \\
\text { Identify test configuration } \\
\text { Identify test parameters } \\
\text { (recorded on paper) }\end{array}$ & $\begin{array}{c}\text { Write test reports } \\
\text { Identify test configuration } \\
\text { Identify test parameters } \\
\text { (stored in computer) }\end{array}$ \\
$\begin{array}{c}\text { Test setup } \\
\text { and execution }\end{array}$ & $\begin{array}{c}\text { Manually change configuration } \\
\text { Physcally perform test } \\
\text { procedures }\end{array}$ & $\begin{array}{c}\text { Execute procedures } \\
\text { electronically }\end{array}$ \\
$\begin{array}{c}\text { Monitor test } \\
\text { results }\end{array}$ & $\begin{array}{c}\text { Monitor strip charts, lights, } \\
\text { and simulation displays }\end{array}$ & $\begin{array}{c}\text { Central monitoring of all } \\
\text { predetermined data }\end{array}$ \\
& $\begin{array}{c}\text { Information physically } \\
\text { distributed }\end{array}$ & $\begin{array}{c}\text { Flexible formats, graphics } \\
\text { displays }\end{array}$ \\
$\begin{array}{c}\text { Analyze test } \\
\text { results }\end{array}$ & $\begin{array}{c}\text { Analyze strip charts and } \\
\text { listings after testing }\end{array}$ & $\begin{array}{c}\text { Near real-time analysis of } \\
\text { test data }\end{array}$ \\
$\begin{array}{c}\text { Assemble test forms, copy } \\
\text { documentation }\end{array}$ & $\begin{array}{c}\text { All pertinent data } \\
\text { maintained by data base }\end{array}$ \\
\hline
\end{tabular}

Table 5 Factors in defining an FMET matrıx

\begin{tabular}{l} 
Aircraft states, including \\
Mach number \\
Altitude \\
Inertial rates \\
Landing gear position \\
Weight on wheels \\
Devices, including \\
Electrical power \\
Interial sensor \\
Rate gyro \\
Analog/digital converter \\
Memory \\
Actuator command link \\
Display \\
Failure modes, including \\
Random noise \\
Hard over \\
Ramp \\
Oscillatory \\
Null \\
Pllot inputs, including \\
Pitch stick \\
Trim \\
Mode selection \\
\hline \hline
\end{tabular}




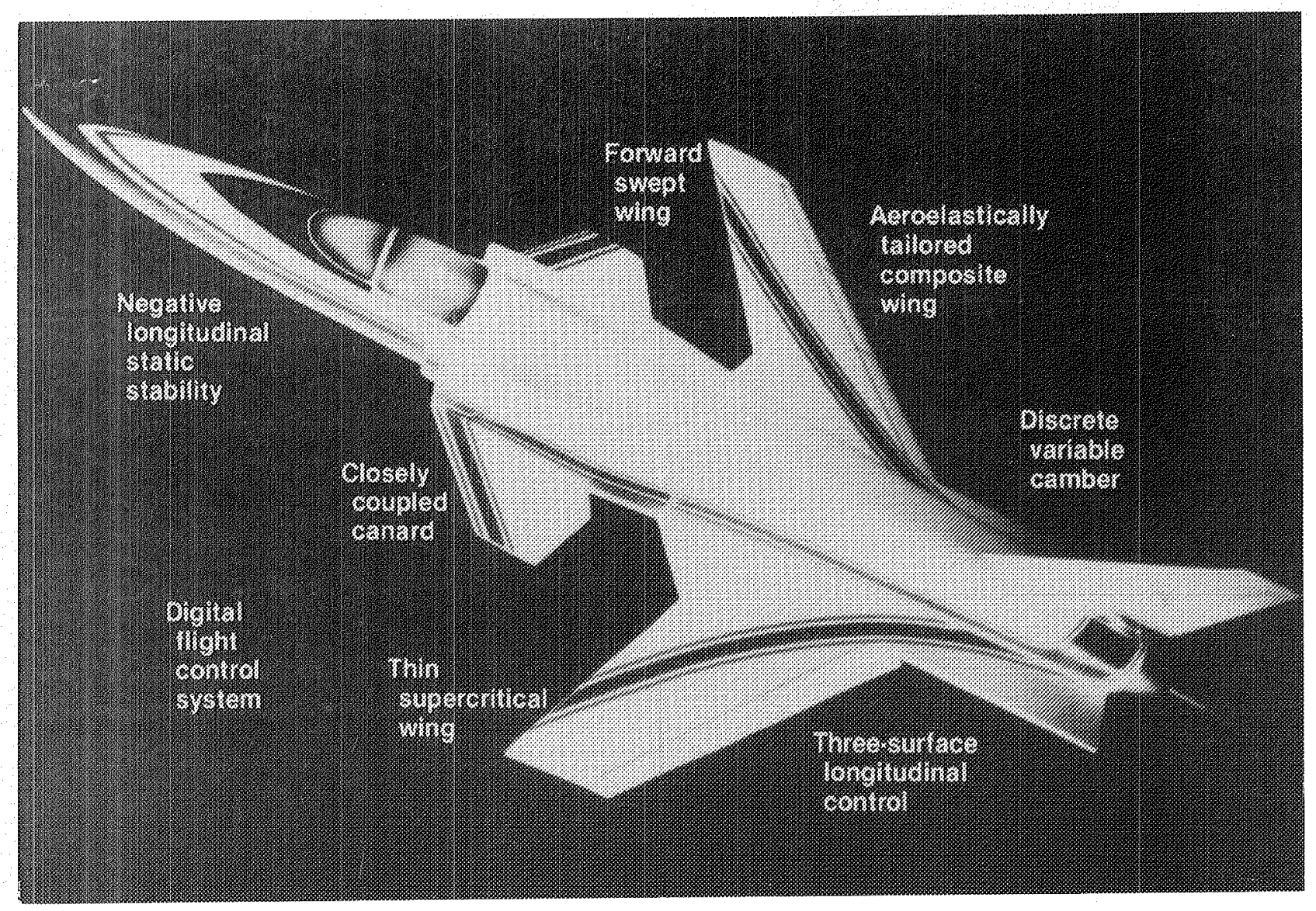

Fig. 1 Overview of $x-29$ technologies. 


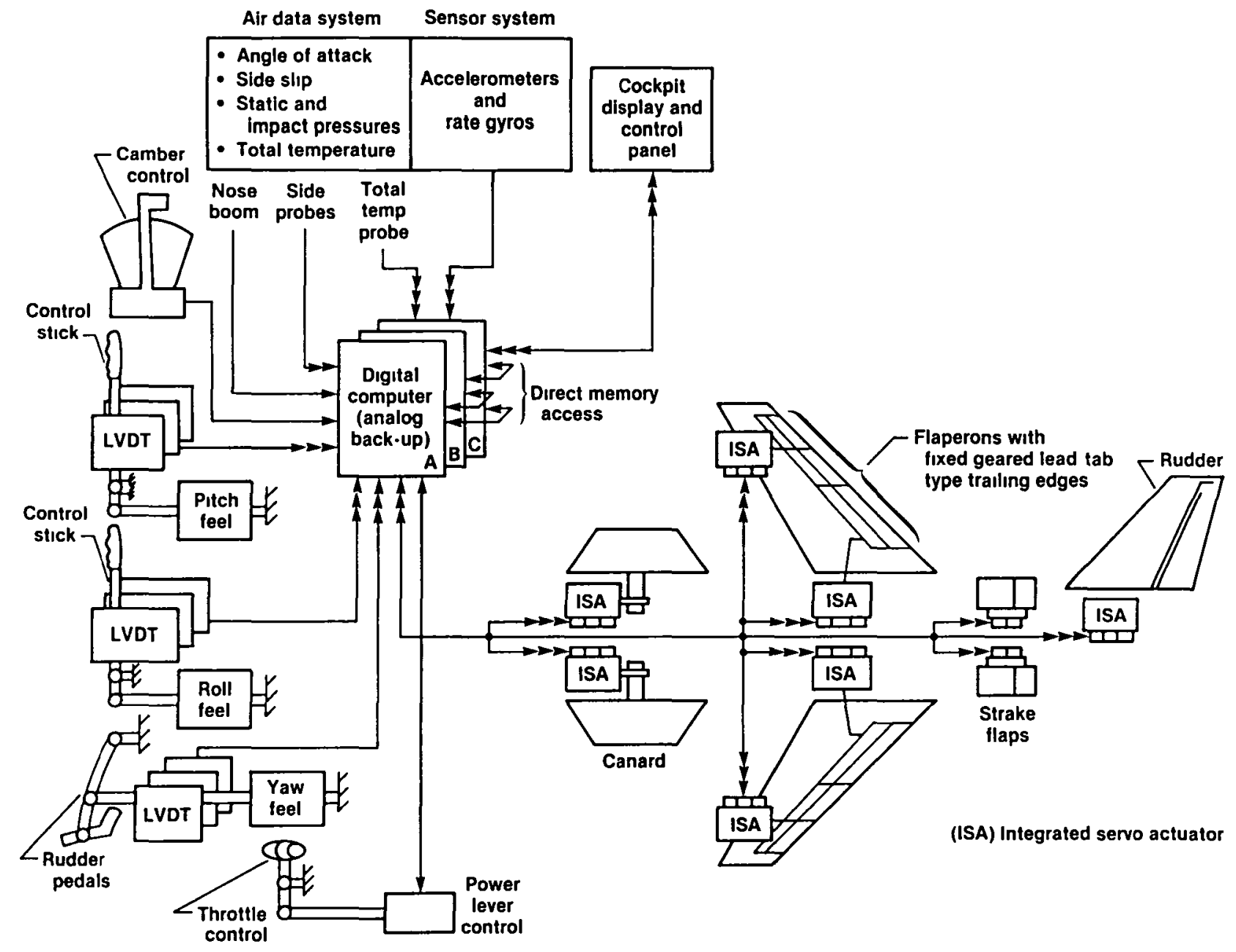

Fig. 2 x-29 flight control system.

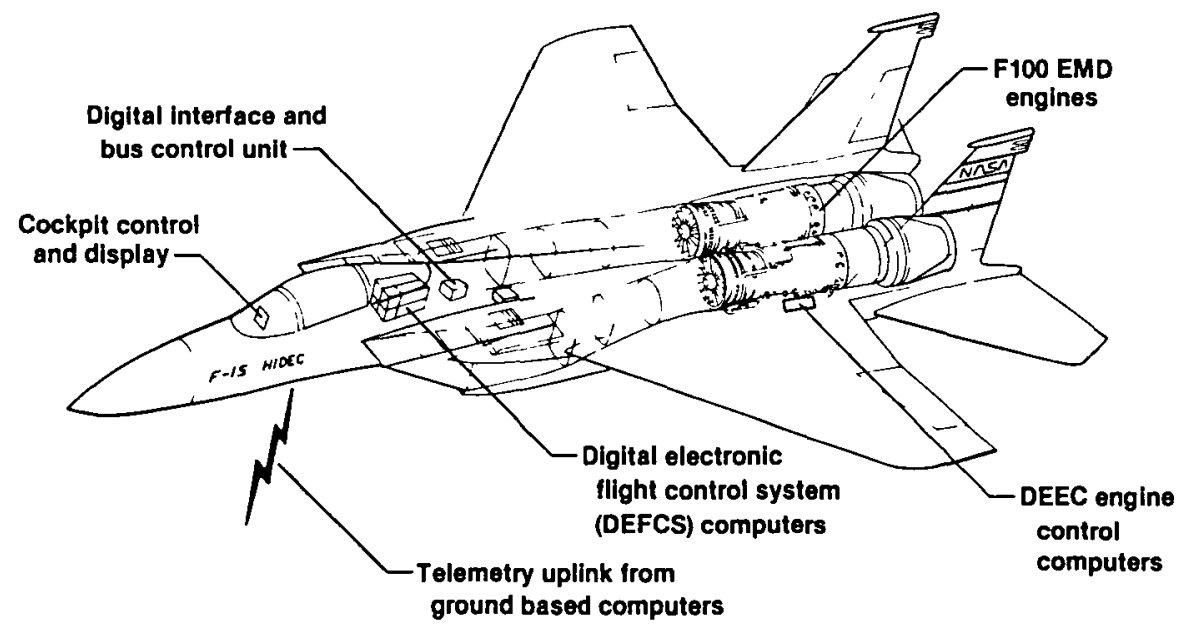

Fig. 3 Features of the F-15 HIDEC research alrplane. 


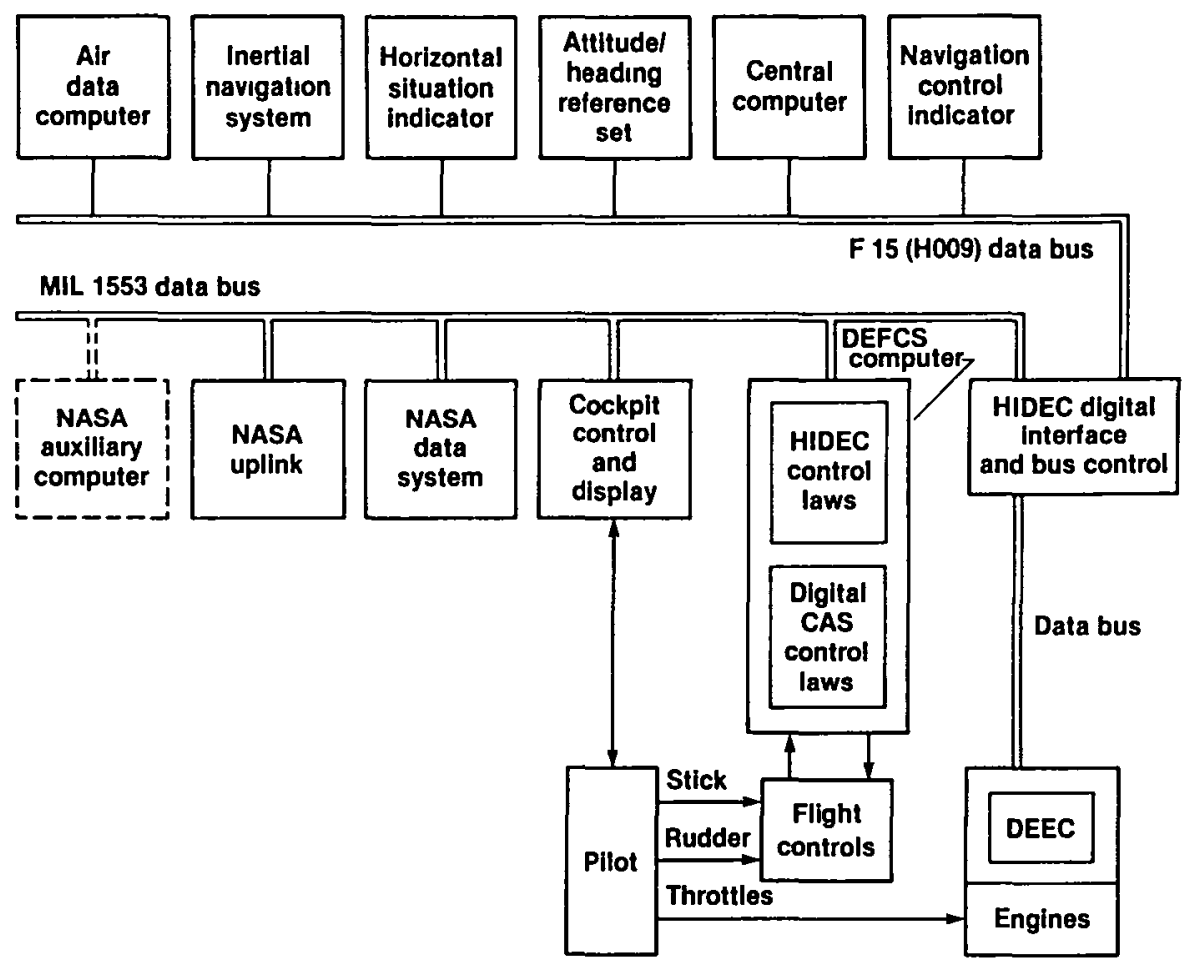

F1g. 4 Block diagram of the HIDEC system.

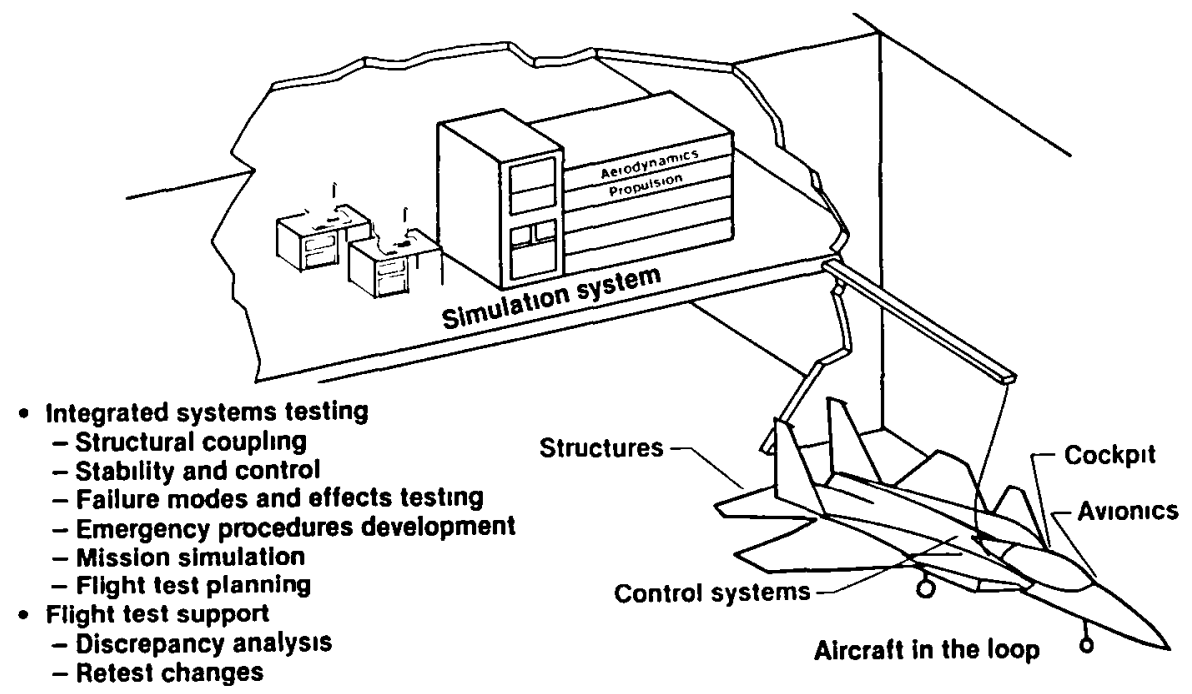

Fig. 5 Alrcraft-in-the-loop configuration. 


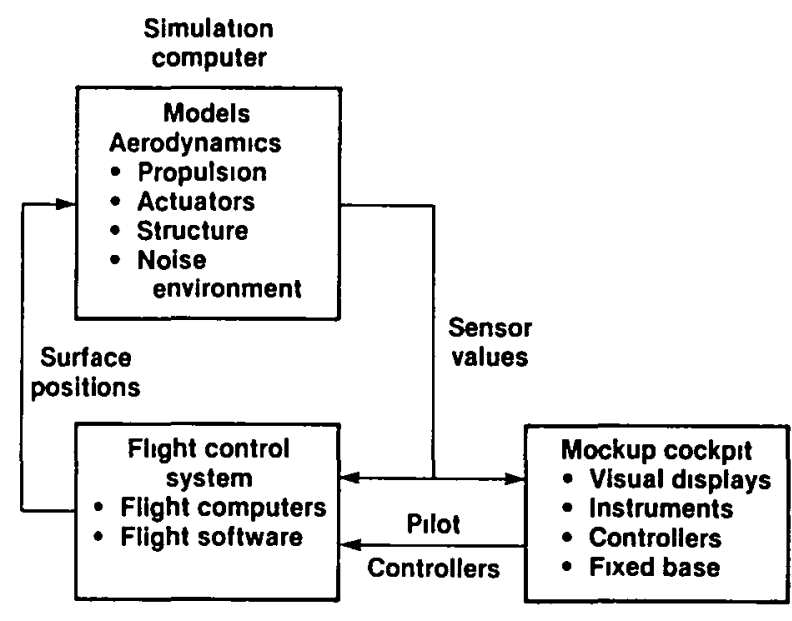

Fig. 6 Hot-bench simulation.

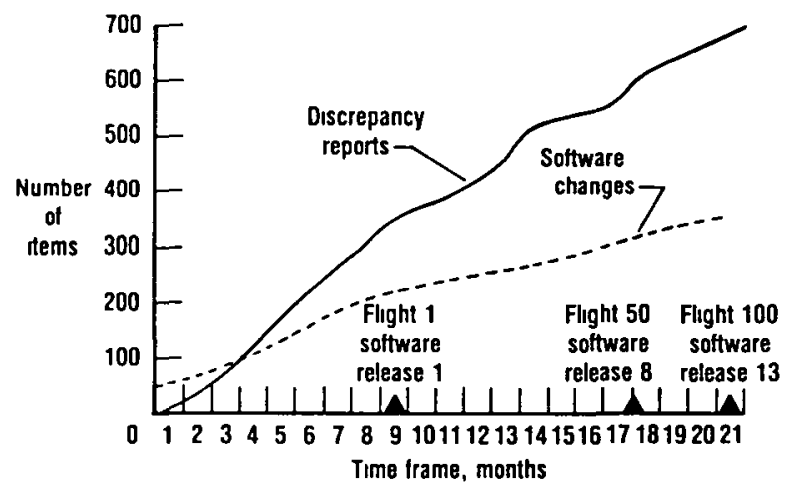

F1g. 7 History of discrepancies and changes for an integrated systems alrcraft.

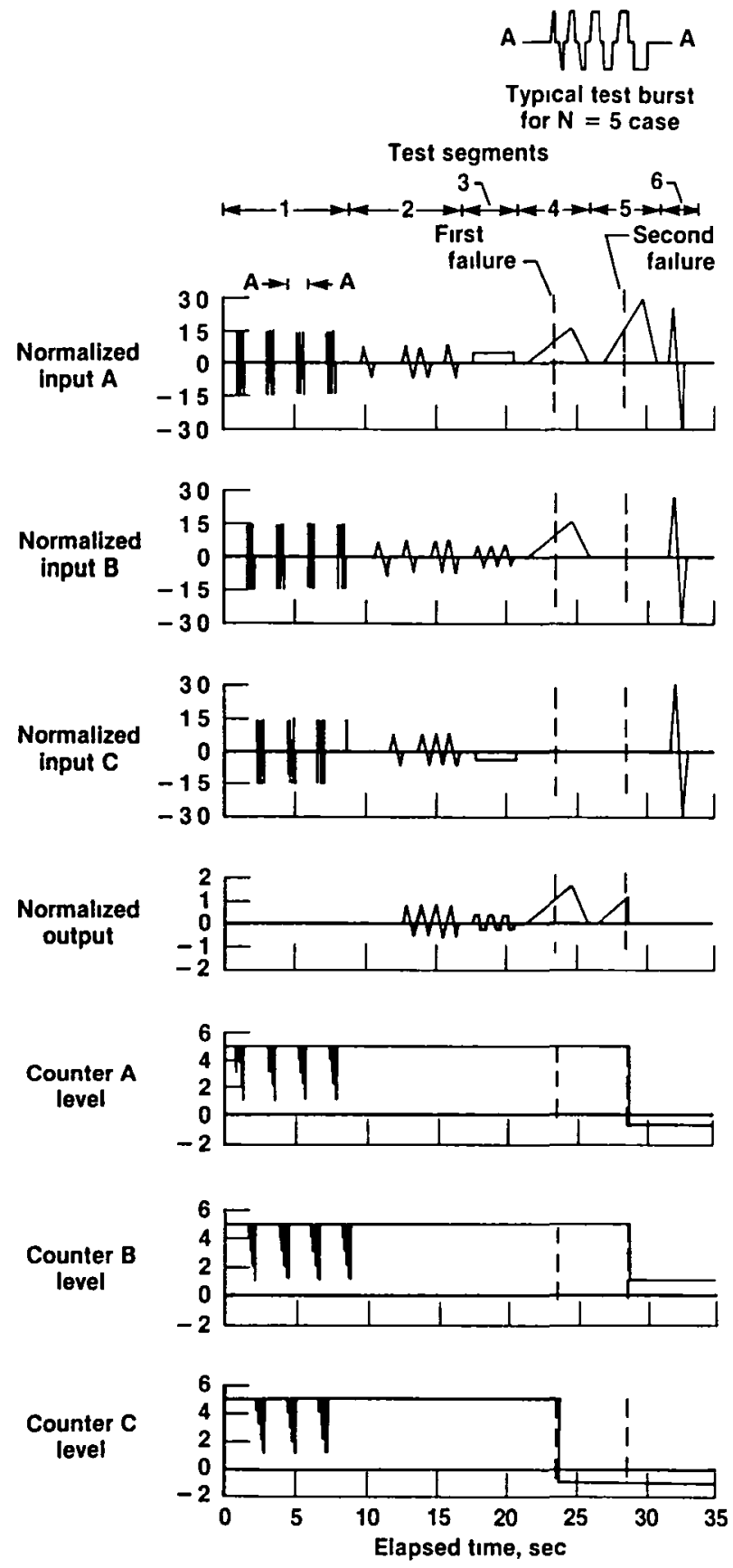

Fig. 8 Automated test sequence for sensor inputs. 


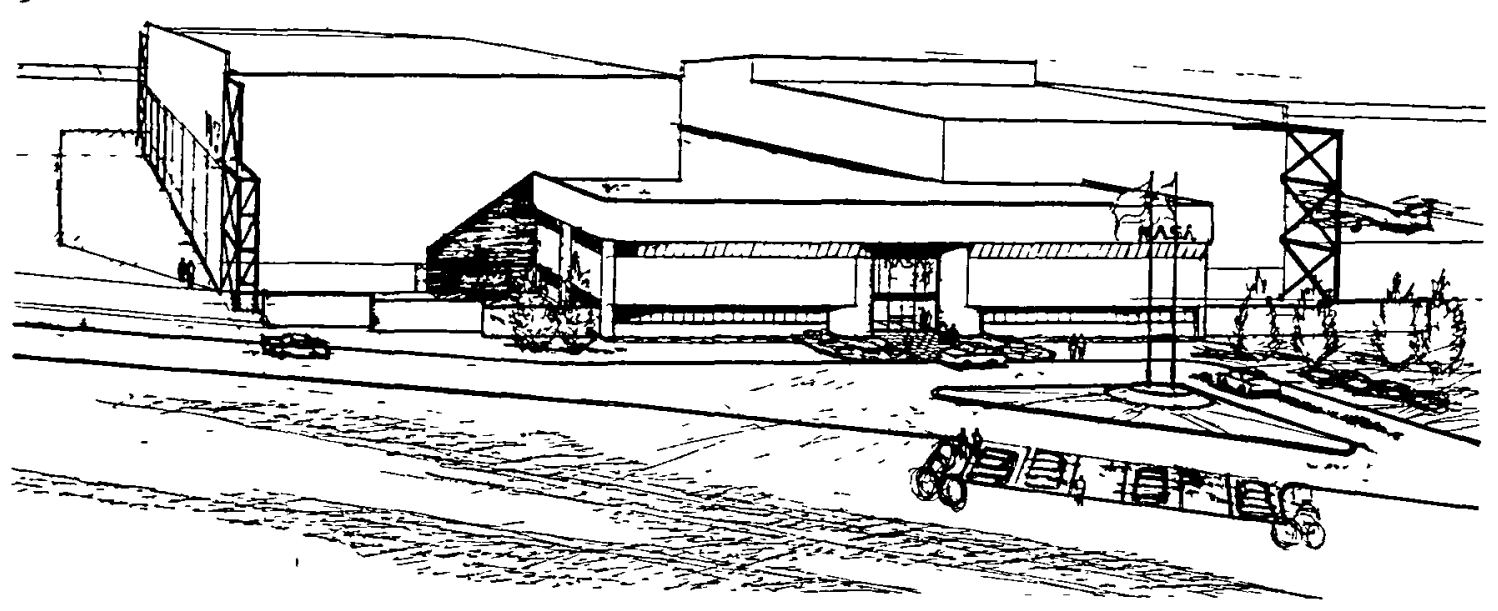

F1g. 9 The Integrated Test Facility.

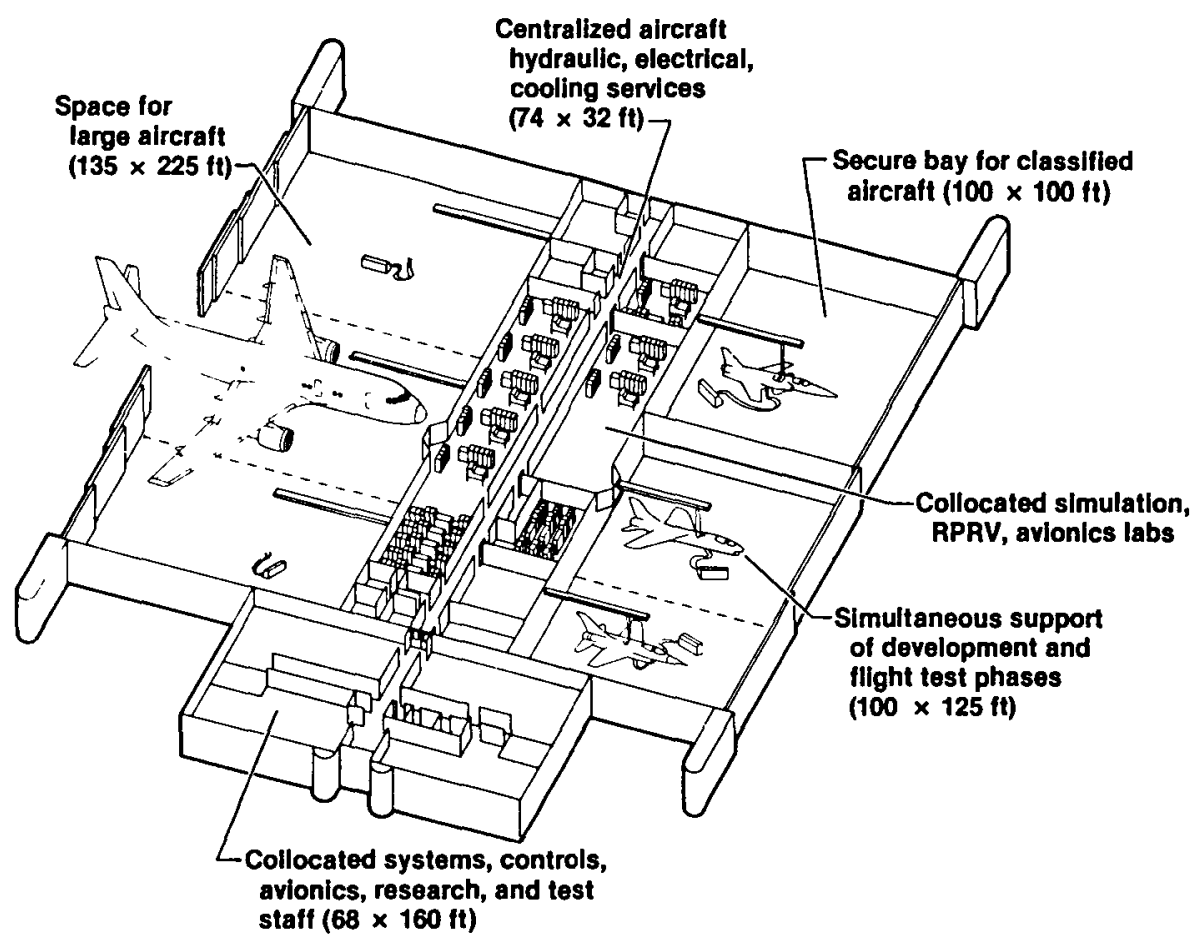

F1g. 10 Integrated Test Facility layout. 


\begin{tabular}{|c|c|c|}
\hline 1 & $\begin{array}{l}\text { Report No } \\
\text { NASA TM-86731 }\end{array}$ & 3 Recipient's Catalog No \\
\hline \multirow[t]{2}{*}{4} & \multirow[t]{2}{*}{$\begin{array}{l}\text { Title and Subtitle } \\
\text { QUALIF ICATION NEEDS FOR ADVANCED INTEGRATED AIRCRAFT }\end{array}$} & $\begin{array}{l}5 \text { Report Date } \\
\text { July } 1985\end{array}$ \\
\hline & & 6 Performing Organization Code \\
\hline \multirow{2}{*}{\multicolumn{2}{|c|}{$\begin{array}{l}7 \text { Author(s) } \\
\text { Dale A. Mackall }\end{array}$}} & $\begin{array}{l}8 \text { Performing Organization Report No } \\
\mathrm{H}-1291\end{array}$ \\
\hline & & \multirow{2}{*}{10 Work Unıt No } \\
\hline \multirow[t]{3}{*}{9} & \multirow{3}{*}{$\begin{array}{l}\text { Performing Organization Name and Address } \\
\text { NASA Ames Research Center } \\
\text { Dryden Flight Research Facility } \\
\text { P.0. Box } 273 \\
\text { Edwards, CA } 93523\end{array}$} & \\
\hline & & 11 Contract or Grant No \\
\hline & & \multirow{2}{*}{$\begin{array}{l}13 \text { Type of Report and Period Coverec } \\
\text { Technical Memorandum }\end{array}$} \\
\hline \multirow[t]{2}{*}{12} & Sponsorıng Agency Name and Address & \\
\hline & $\begin{array}{l}\text { National Aeronautics and Space Administration } \\
\text { Washington, D.C. } 20546\end{array}$ & $\begin{array}{l}14 \text { Sponsoring Agency Code } \\
\text { RTOP } 533-02-61\end{array}$ \\
\hline \multicolumn{3}{|c|}{5 Supplementary Notes } \\
\hline & \multicolumn{2}{|c|}{$\begin{array}{l}\text { Prepared for presentation at American Institute of Aeronautics and Astronautics } \\
\text { Conference, Snowmass, Colorado, August } 19-21,1985 \text {. }\end{array}$} \\
\hline
\end{tabular}

16 Abstract

In an effort to achieve maximum aircraft performance, designers are integrating aircraft systems. The characteristics of aerodynamics, vehicle structure, and propulsion systems are being integrated and controlled through embedded, often flight-critical, electronic systems. This paper addresses the qualification needs for such highly integrated aircraft systems. Based on flight experience with research aircraft, a set of test capabilities is described which allows for complete and efficient qualification of advanced integrated aircraft.

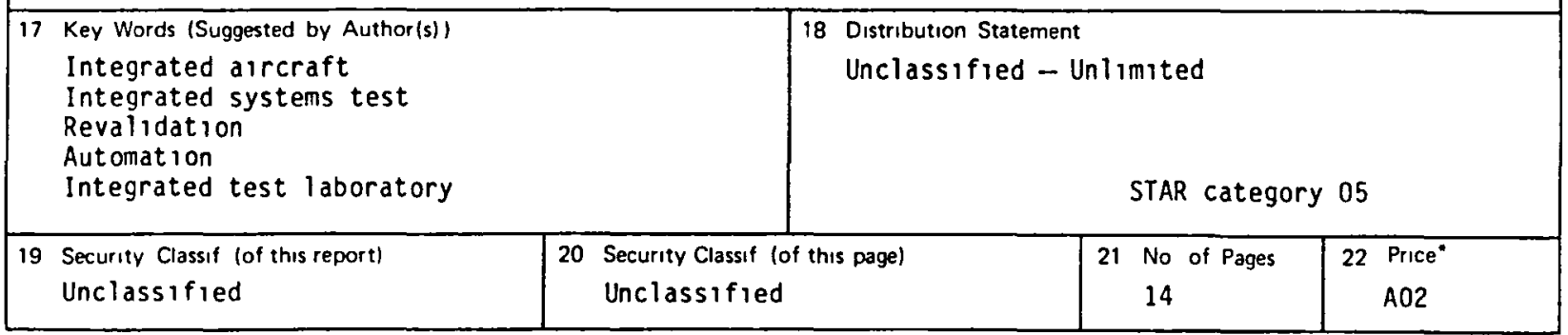

*For sale by the National Technical Information Service, Springfield, Virginia 22161. 
End of Document 